\title{
An Update on Major Lower Limb Amputation in Nigeria
}

\author{
Edomwonyi E. O., Onuminya J. E. \\ Department of Orthopaedics and Traumatology Irrua Specialist Teaching Hospital, Irrua, Edo State, Nigeria
}

\begin{abstract}
This paper is our recent review of literatures on lower limb amputation in Nigeria. There is no national data on the incidence of amputation in Nigeria. Its management remain a major health problem in our society. Amputee in Nigeria is often confronted with the physical reality of mutilation and the stigma attached to it, making it difficult for patients to accept the therapeutic value of amputation unless they perceive an obvious threat to life. The pattern of indications vary from place to place and seems to be changing. Rehabilitation of amputees is a major problem in Nigeria. It is multidisciplinary and should begin from the time the decision is made. This should be co-ordinated in a well organized amputee clinic. Most of the amputees do not have access to prosthesis so they hop around with the aid of sticks, crutches and join the colony of beggars and destitute in our streets. Efforts should be channelled towards preventing limb losses and reducing the burden on amputees through the initiation of new and enforcement of existing health policies in Nigeria.
\end{abstract}

Keywords: Lower Limb, Amputation, Major, Review, Nigeria.

\section{Introduction}

Amputation is the removal of the whole or part of a limb through bone or joint. It is one of the oldest surgical procedures dating back to prehistoric times. It was described in the Babylonian code of Hammurabi inscribed on black stone in $1700 \mathrm{BC} .{ }^{1}$ Early surgical amputation was a crude procedure by which a limb was rapidly severed from an unanaesthetized patient. The open stump was then crushed or dipped in boiling oil to secure haemostasis. The procedure was associated with a high mortality rate. For those who survived, the resulting stump was poorly suited for prosthetic fitting ${ }^{2}$

According to newest statistics in the USA, about 1.7 million people live with amputations ${ }^{3}$ and the number has increased in recent years ${ }^{4}$. It is estimated that 25-27 in 100,000 of the German population have undergone amputation ${ }^{5}$. Data from Nigeria is sparse, but onuba et $\mathrm{al}^{6}$ reported that $0.38 \%$ of all orthopaedic operations were amputations. Thanni ${ }^{7}$ reported 1.6 per 100,000 as the estimated prevalence of extremity amputation in Nigeria. It is important to note that there are no national data.

Rural people view amputation even more seriously. For them, surgery of any kind is accompanied by fantasies, helplessness, and mutilation, loss of control, body image distortion, castration, rejection and death. All these fantasies, in and out of awareness create massive anxiety. The person who has lost a limb must confront not only the physical reality of mutilation but also, the body image changes associated with it and the personal meanings they carry ${ }^{8}$. In Nigeria, the traditional beliefs of reincarnation with a missing part or living after death with a deformity make it increasingly difficult for them to accept amputation.

Limb amputation is considered the last resort when limb salvage is impossible or when the limb is dead or dying, viable but non functional or endangering the patient's life ${ }^{9}$. Limb loss by an individual in developing countries like Nigeria where the prosthetic services is poor often has profound economic, social and psychological effects on the patient and their families. ${ }^{10-13}$

Major limb amputations are essentially disfiguring operations that carry a fairly high peri-operative mortality and morbidity and persons who have undergone amputations are often viewed as incomplete individuals ${ }^{14}$. In this paper, the authors review the implications of major lower limb amputations in Nigeria.

\section{Indications vary within and between countries.}

\section{Indications}

Limb gangrene arising from trauma as well as traditional bone setters (TBS) intervention were the leading indications for limb amputations in Nigeria in $60 \%$ of cases. ${ }^{12,13,15-17}$ Recently, reports ${ }^{18-20}$ from the south-south and south western parts of Nigeria revealed that diabetic foot gangrene alone was the leading indication for major lower limb amputation, with figures as high as $42 \%-45 \%$. A rising incidence of diabetic foot gangrene as an indication, had earlier been reported by other authors from the same region with figures as high as $26-29 \%$. Earlier reports ${ }^{6,23}$ from Maiduguri,north western part of Nigeria, showed that malignancies was the commonest indication, but more recent report ${ }^{24}$ from the same centre pointed to trauma. The inappropriate splintage of fractures by the TBS resulting in iatrogenic limb gangrene is an absolute indication for amputation. These cultural practices remain a major health problem in our society. Other local reports ${ }^{12,25}$ recorded bone 
tumour, uncommon indications include burn contracture ${ }^{26}$ vascular insufficiency, congenital anomalies, chronic osteomyelitis(complicating TBS treatment of open fractures) ${ }^{12,13}$.

Most amputee patients in developed countries are older than 60 years of age, and 80-90\% of lower limb amputations are performed as a result of vascular problems ${ }^{14,26-28}$. In Nigeria, majority of amputees are young, ${ }^{6,29}$ and the indication for limb amputation varies from place to place and most often they present very late when limb salvage is not a viable option.

Indications differ a little in other parts of Africa. Sepsis was reported to be the commonest indication in Sudan $^{31}$, Trauma in Tanzania ${ }^{22}$ and several parts of east Africa ${ }^{32}$ and diabetic foot gangrene in Ghana. ${ }^{33}$

\section{Types And Level Of Amputation}

Provisional (two-stage) amputation is commonly performed in Nigeria ${ }^{6,12,13,15,25,34,35}$ as well as other African countries ${ }^{31}$ for the gangrenous limb with ascending sepsis, occasionally complicated by diabetes or associated with TBS intervention. This is done in an attempt to control ascending infection, blood sugar and reduce the risk of stump wound breakdown due to sepsis ${ }^{25}$. Wound revision and closure are done when soft tissue conditions improve; and 70-90\% of amputation in Nigeria are performed in the lower limbs. ${ }^{1,16,20,25,35}$ The lower limbs are more often injured than the upper limbs and diabetic gangrene is commoner on the foot than elsewhere on the body ${ }^{25}$.

In Nigeria, below knee (BK) amputation is the leading level of amputation. ${ }^{16,18,20,24,25,35}$. This is followed by above knee (AK) amputations giving an AK/BK ratio 1:2 in Nigeria ${ }^{12,20,25}$.

\section{Site of Amputation}

Determining the appropriate level of amputation, requires an understanding of the trade-offs between increased function with a more distal level of amputation and a decreased complication rate with a more proximal level of amputation.

In spite of the modern reconstructive attitude of creating a dynamic functional stump, the most distal level consistent with primary wound healing, the site of the disease and blood supply of the limb ultimately dictates the level at which successful amputation may be performed. ${ }^{36}$

Pre-operatively clinical parameters such as lowest palpable pulse, skin temperature, hair-growth and bleeding at surgery have been used with various degrees of success to predict healings of amputation sites. ${ }^{37-42}$ This is still the experience in most centres in Nigeria. Pre-operative arteriograms are of little help in determining potential for wound healing ${ }^{2}$. Segmental systolic blood pressures likewise offer little useful information because they are often falsely elevated to the non-compliant walls of artheriosclerotic vessels.

Measurement of skin flap perfusion, through thermography, laser Doppler flowmetry however, may be of some benefit. Transcutaneous oxygen measurement is the most beneficial. The test is performed by inserting a probe that is heated to $45^{\circ} \mathrm{C}$ for 10 minutes before oxygen tension is measured, allowing a maximum vasodilatory response and thus a more accurate determination of perfusion potential. ${ }^{2}$ Various studies have recommended different cut off levels ranging from $20-40 \mathrm{mmHg}$, for "good" healing potential. Energy expenditure is markedly elevated in more proximal amputations.

\section{Nutrition}

Protein malnutrition increases the rates of morbidity and mortality among hospitalized patients. ${ }^{43,44}$ Cell mediated and humoral immunity systems are impaired, with resultant decrease in host resistance ${ }^{45}$. Trauma or infection increases energy requirements by $30 \%$ to $55 \%$ above basal values. Patients undergoing, lower extremely amputations often are elderly and debilitated, young and may have had severe trauma or diabetics with dysvascular limbs with open wounds and systemic sepsis, causing increased metabolic demands.

A base line nutritional assessment should be done including serum album and total lymphocyte count. If time permits, enteral or intravenous hyperalimentation should be considered for a malnourished patient being evaluated for amputation.

\section{Antibiotics}

In cases of open, draining wounds or gas forming infection, the use of antibiotics in the perioperative period is mandatory. In neurotrophic ulcers in diabetes mellitus, the infection is usually polymicrobial anaerobic and aerobic species. ${ }^{46,47}$ Broad spectrum(Parenteral) antibiotics should be commenced until specific organisms are recovered in culture and continued until sepsis is quiescent. In cases of noninfected dysvascular amputation, prophylactic antibiotics e.g. cephalosporin are begun at the time of surgery and continued for 48 hours after the amputation. 


\section{Surgical Technique}

In lower limb amputations, a tourniquet may be used but exanguination by wrapping with an elastic bandage is contraindicated in Ischaemic limbs, infected limbs and limbs being amputated for cancer. Skin should be handled in a non-traumatic manner, especially in dysvascular patients.

In severely infected limbs or traumatized limbs with significant muscle necrosis, the stump should be left open (guillotine). Open or guillotine amputation is commonly employed to save life. After life has been salvaged and infection controlled, a second stage revision and closure is done with design of proper flaps.

Flaps should be kept thick. Unnecessary dissection should be avoided to prevent further devascularisation of already compromised tissues. Covering the end of the stump with a sturdy soft tissue envelope is of utmost importance. Scar should not be adherent to the underlying bone. Redundant soft tissues or large dog ears should be avoided.

Muscles are divided at least $5 \mathrm{~cm}$ distal to the intended bone section and stabilized by myodesis or myoplasty. Myodesed muscles continue to counter balance then antagonists, preventing contractures and maximizing residual limb function. However, myodesis may be contraindicated in severe Ischaemia because of the increased risk of wound breakdown.

\section{Hemostasis}

Major blood vessels should be isolated and individually ligated. Large blood vessels should be doubly ligated. Tourniquet should be deflated before closure and meticulous hemostasis should be obtained. A drain should be used in all cases.

\section{Nerves}

Nerves should be isolated, gently pulled distally into the wound, and divided cleanly so that the end retracts well proximal to the level of bone resection. Large nerves like the sciatic often contain relatively large arteries and therefore should be ligated. Strong tension as well as crushing should be avoided so as to avoid formation of painful neuromas. End-loop anastomosis, perineural closure, silastic capping, sealing the epineural tube with butyl - cyanoacrylate, sealing, cauterization are all methods that have been used to bury nerve ends in bone or muscles.

\section{BONE}

Resection is done such that no prominence is left without adequate soft tissue padding. Remaining bone should be rasped to form a smooth contour. This is specially important in locations such as anterior aspect of tibia and lateral aspect of femur.

Excessive periosteal stripping is contraindicated so as to prevent ring sequestra or bony overgrowth.

i. Open amputation is one in which the skin is not closed over the end of the stump. It is the first of at least two operations required to construct a satisfactory stump. It must always be followed by secondary closure, re-amputation revision or plastic repair. The purpose is to prevent or eliminate infection. It is indicated in infections and in severe traumatic wounds with extensive destruction of tissue and gross contamination by foreign material. Appropriate antibiotics are given until the stump is finally healed. It is of two types: Open amputation with skin flaps and

Circular open amputations (guillotine). Open amputations are commonly employed to save life.

In Nigeria, below knee amputation is the commonest level of amputation. ${ }^{16,18,20,24,25,35}$ Salvage of the important knee joint at this level, significantly enhances the probability of successful rehabilitation ${ }^{48,49}$

The ideal length of the below knee stump is the one compatible with acceptable functions. Experience has shown that elective amputation in the middle third of the tibia, regardless of measured length, provides a well padded, biomechanically sufficient lever arm and a functional stump that can easily be fitted with a modern below knee prosthesis ${ }^{48}$. In those cases in which a very short below knee amputation is necessary, the head of the fibula is not resected but left in place to provide a broad stump for improved prosthesis control. It is felt that the broader squared-off stump provides enhanced weight bearing and rotational stability for improved control of the modern total contact patella tendon bearing prosthesis. The below knee (BK) stump provides the amputee with the means for voluntary knee control and an anatomical structure capable of weight bearing. The preservation of the knee with its reduced energy requirement and its proprioceptive function, enables the patient to use a prosthesis with relative ease. The BK prosthetic weight bearing is circumferentially borne by the tibial condyles and patella tendon.

For the above knee amputation, a proximal amputation through the distal half of the femur, preferably at the junction of the middle and distal thirds, heal well, provides an adequate lever arm for prosthetic operation and allows enough room for proper placement of prosthetic components. Amputations through the proximal third of the femur is associated with a loss of muscle control with an inefficient short lever arm and greater energy expenditure. Functionally and prosthetically, amputation within $5 \mathrm{~cm}$, of the lesser trochanter must be 
considered a hip disarticulation in providing a greater weight bearing area. ${ }^{48}$ The energy expenditure required for walking with an above knee prosthesis is significantly increased. The above knee (AK) prosthetic weight bearing is total Ischeal and the thigh Corset often rotate making sitting difficult. ${ }^{50}$

\section{Post Operative}

This requires multidisciplinary team approach. This includes the surgeon, internal medicine specialist, physiotherapist, occupational therapist, psychologist, social worker, prosthetist. All the same, precaution are followed as for any major orthopaedic surgery including; preoperative antibiotics, deep vein thrombosis (DVT), and pulmonary hygiene. Pain management includes the brief use of parenteral narcotics followed by nonsteroidal anti Inflammatory drugs (NSAIDS) that is tapered as soon as tolerated.

Over the past thirty years, there has been a gradual shift from the use of "conventional" soft dressing to the use of rigid dressings, especially in centers performing significant numbers of amputations. Rigid dressing consists of Plaster of Paris Cast that is applied to the stump of the conclusion of surgery. It may be successfully and beneficially employed at essentially all levels of amputations and are applicable to all age groups.

Rigid dressings offer several advantages over soft dressings.

- Rigid dressings prevent oedema at the surgical site,

- protect the wound from bed trauma, enhance wound healing and early maturation of the stump, decrease postoperative pain, allows earlier mobilization from bed to chair and ambulation with support.

Drains are removed at forty-eight hours or when it ceases to function. Stump is elevated by raising the foot of the bed which help manage edema and postoperative pain. With transfemoral amputation, patient is cautioned against placing a pillow between thighs or beneath the stump or otherwise keeping the stump flexed or abducted so as to prevent flexion and abduction contractures.

Exercises for the stump is commenced under the supervision of physiotherapist the day after surgery or as soon thereafter as tolerated, muscle-setting exercises followed by exercises to mobilize the joints. Within the first few days after lower extremity amputation, ambulation is commenced using parallel bars, then walker or crutches are used when they gain control of the limb and are comfortable enough.

The optimal time to begin prosthetic ambulation with protected weight-bearing depends on a number of factors including age, strength, agility of the patient as well as the patients' ability to protect the amputation stump from injury as a result of excessive weight-bearing. Any weight before the stump is healed should be strictly supervised.

Regardless of when prosthetic ambulation is begun, rigid dressing should be removed and wound inspected in $7-10$ days. If the wound is healing well, a new rigid dressing is applied. Cast should be changed weekly until wound is healed. Bathing and stump hygiene, application of elastic stump shrinker is commenced. Continued gentle stump compression is done. Use of rigid dressing is continued until the stump volume appears unchanged from the previous week, at which time the prosthetist may apply the first prosthesis.

\section{Complications}

The mortality rate associated with amputation in Nigeria ranges from $8 \%-11 \%{ }^{6}, 12,20,25$ due to septicaemia and diabetic complications, $9 \%$ and $11 \%$ were reported in East Africa ${ }^{32}$ and Ivory Coast ${ }^{52}$ respectively. Other reported complications include stump sepsis, stump oedema, blisters, wound dehiscence, ulceration, contractures, chronic osteomyelitis of the bony stump and phantom limb syndrome.

Stump oedema develops when elastic compression wound dressings are applied instead of rigid plaster dressing. Further, if the compression dressing is poorly applied, the edema may not be symmetrical. Sometimes the above knee stump is dressed without including the end, a dumbbell shaped stump results. Occasionally, the above knee amputee may only bandage the stump partially as to the mid portion of the stump rather than fully into the groin and an "adductor" or proximal tissue roll may develop, which may hinder the fitting of a definitive prosthesis. The above knee stump should be wrapped completely into the groin area maintaining the placement by a spica bandage about the waist ${ }^{51}$.

Stump sepsis is the commonest reported complication in Nigeria. ${ }^{6,16,19,20,29,35,53,54}$ The risk of postoperative wound infection is often increased by pre-operative conditions of the limb in addition to other comorbidities the patient may have. Diabetes foot gangrene with ascending sepsis, gangrene with sepsis from TBS treatment of limb injuries increases the risk of postoperative wound infection. This could involve flap necrosis in some cases. Peri-operative antibiotics administration as highlighted earlier is mandatory.

Joint Contractures may affect any of the proximal joints in the lower limb that remain after an amputation. In the above knee amputee with a short stump, abduction - flexion join contracture may be noted.

To prevent such contractures the surgeon should instruct the patient to avoid the use of stump elevating pillows and further, to avoid the usually more comfortable abducted externally rotated position at some time each day to decrease the possibility of hip contracture, particularly in the above knee stump. The patient should also be instructed to adduct the stump many times each day to minimize the development of an abduction 
contracture in short above knee stump ${ }^{48}$. The use of Immediate Postoperative fitted prosthesis has decreased the incidence of joint contractures. In the usual rigid plaster dressing, the knee joint is maintained in only a few degrees of flexion, and this had minimised the severe contractures often seen when the classic surgical technique is employed. If a rigid plaster dressing is not used in the below knee amputee, it is important for the surgeon to remind his patients to fully extend the knee joint repeatedly in order to avoid flexion contractures.

The treatment of fixed flexion contractures of the short below knee stump entails a prolonged period of heat, massage and passive stretching of the joint with considerable discomfort to be endured by the patient. In some patients, prosthetic modifications may be necessary to adapt to the contracture. Rarely, severe fixed contractures may require treatment by wedging casts or surgical release of the contracted tissues.

Chronic Osteomyelitis may complicate amputation surgery leading to formation of bone sequestrum which subsequently may result in a draining sinus in a healed amputation stump. This may be iatrogenic as highlighted earlier. Radiograph is required to identify the "ring sequestrum" present. Drainage usually persist until the bony sequestrum is removed.

Phantom limb sensation remains a problem for the amputees in our practise. Most amputees say that they remain aware of the ablated portion of the limb. The phantom limb sensation is simply an awareness of some of the missing portion. Most amputees do not indicate an awareness of the entire missing section, but perhaps only of the most active areas. The patient likewise may relate that as time progresses the phantom may progress closer to the end of the stump, a situation that has been called "telescoping". ${ }^{2} 51$ It is occasionally a pleasant sensation. Phantom limb sensation may fade away quickly or may persist for many years.

Unfortunately, in some cases, the phantom limb sensation becomes painful. There are early and late peaks of onset of phantom limb pain at one month and one year after amputation respectively. ${ }^{55}$ Fortunately, phantom pain develops in less than $2 \%$ of all amputees although some report an incidence as high as $10 \%{ }^{20,51 \text {, }}$ 55, 56 The phenomenon is thought to develop from either a central problem (basically psychogenic) or a peripheral problem (basically organic) ${ }^{56}$ which is the current thinking. It has been described as a constant burning type of pain similar to that noted in causalgia. It has also been described as a continuous shooting or stabbing type of pain similar to that caused occasionally by neuromas ${ }^{56}$. Once significant pain is established, however, it can be extremely difficult to treat. Although no one method is universally beneficially, some patients may benefit from diverse measures as massage, ice, heat, increased prosthetic use, relaxation training, low feedback, sympathetic blockade, local nerve blocks, epidural blocks, ultrasound, trans-cutaneous electrical nerve stimulation and placement of a dorsal column stimulator. ${ }^{2}$ Dorsal chordotomies, prefrontal cerebral lobotomies and drug treatment with LSD. ${ }^{57}$

In view of the many methods advised, it is fairly obvious that none is a panacea for this rather dreadful situation. Certainly, each amputee with phantom pain should have a psychologic and psychiatric evaluation to aid in identifying and perhaps helping to remove factors that may contribute in this area. ${ }^{51}$

\section{Rehabilitation}

Rehabilitation of the amputees is a major problem in Nigeria. ${ }^{6,12,20,25}$

The fact is that our amputee patients have to travel hundreds of kilometres to secure prosthesis in the few centres where such facilities are available. This is neither practical nor acceptable.

It is not even affordable for the majority. Reports ${ }^{18,20}$ revealed only $9-12 \%$ of amputee patients have prosthetic fitting in Nigeria. The rest are crutch ambulators, few spent most of their walking hours on a wheel chair and several are dependent on relatives. In Nigeria, the society still views amputees with suspicion ${ }^{6}$. This makes rehabilitation for them a problem, be it social, occupational and otherwise.

Provision, maintenance and replacement of the artificial limb should be responsibility of health care providers as well as the government. ${ }^{58}$ This laudable principle of amputation surgery is hardly met in Nigeria due to lack of prosthesis and funds. (59)

In the Nigerian setting, it is perhaps advisable to prescribe immediate Post-operative fitting of a temporary prosthesis to provide adequate motivation for the patient needing a permanent artificial limb. Such prosthesis relatively are inexpensive and serve to give the patient as well as the physician and therapist an opportunity to evaluate endurance balance, co-ordination, and general overall strength. ${ }^{48}$

Rehabilitation of the below knee amputee is a most rewarding experience particularly when compared with the rehabilitation potentials of higher level amputees. Insofar as the below knee amputee is concerned, there are few, if any contraindications to fitting, provided adequate motivation is present and patient was ambulatory prior to the onset of disability. With the above knee amputation, the patient must possess in addition adequate balance, strength, and a satisfactory cardiovascular reserve. This is because of the significant increase in energy expenditure required for walking with an above knee prosthesis. It has been shown that energy costs in the above knee amputee during normal walking speeds, as measured by metabolic requirements, have indicated a $100 \%$ greater demand than in the normal individual. ${ }^{49}$ Considering the common level of lower limb amputation in Nigeria, most amputees need prosthetic rehabilitation and the attending physician need to 
intensify efforts in the pre and post amputation preparation of patients with the view to restore functional ambulation to the amputee where possible.

\section{Conclusion}

Trauma, gangrene resulting from diabetes and TBS intervention are the leading indications for amputation in Nigeria. (59) These are preventable conditions. There is need for government to increase public enlightenment on road safety precautions, establish and equip more trauma centres and specialized diabetic foot clinics.

Widespread education of diabetics on foot care and glycaemic controls including regular blood sugar screening for the aging population cannot be over-emphasized. Government should regulate the activities of TBS.

Functional rehabilitation and prosthetic centres should be established at several and strategic locations in the country. Services should be accessible and affordable to the amputees.

These would go a long way to reducing the incidence of amputation and the burden of the amputees.

\section{References}

[1]. Robinson K.P. Historical aspects of amputation. Ann. Roy Coll. Surg. Engl. 1991; $73: 134-136$.

[2]. Robert K, Heck Jr. General Principles of Amputations. In Canale S.T, Daugherty K, Jones L, Editor(s). Campbell's operative Orthopaedics. $10^{\text {th }}$ edition Pennsylvania, Philadephia; 2003. P. 537.

[3]. Ziegler - Graham K, MacKenzie EJ, Ephraim PL, Travison TG, Brookmeyer R. Estimating the prevalence of limb loss in the United States: 2005 to 2050. Arch. Phys. Med. Rehab. 2008; 89(3): 422 - 9.

[4]. Robert K, Heck Jr. General Principles of Amputations. In Canale S.T, Beaty J.H, Editor(s). Campbell's operative Orthopaedics, $11^{\text {th }}$ Edition. Pennsylvania, Philadephia; 2008 . P. 561 - 78

[5]. Moysidis T, Nowack T, Eickmeyer F, Waldhausen P, Brunken A, Hochlenert D et al. Trends in amputations in people with hospital admissions for peripheral arterial disease in Germany. Vasa. 2011; 40(4): 289 - 95.

[6]. Onuba O, Udoidiok E. The Scope of amputation in developing Countries. Postgraduate Doctor, 1989; $11(5) ; 118-21$.

[7]. Thanni LO, Tade AO, Extremity amputation in Nigeria - a review of indications and mortality. Surgeon 2007 Aug; 5(4): 213 - 7 .

[8]. Wilson GP, Brebs SJM, Coping with amputation. Vascul. Surg. 1983; 17: 165 - 75.

[9]. Paudel B, Shrestha BK, Banskota AK: Two faces of major lower limb amputations. Kathmandu University Medical Journal 2005, 3(11): $212-216$.

[10]. Essoh JB, Bamba J, Dje Bi Dje V, Traore A, Lambin Y; limb amputations in adults in an Ivorian Teaching Hospital, Niger J. Ortho. \& Trauma 2007, 6(2): $61-63$

[11]. Nwankwuo OE, Katchy AU: Surgical limb amputation: a five year experience at Hill top Orthopaedic Hospital, Enugu, Nigeria. Nig. J. Orthop. Trauma 2004, 3: $139-149$.

[12]. Onuminya JE, Obekpa PO, Ihezue HC, Ukegbu ND, Onabowale BO. Major amputations in Nigeria: a plea to educate traditional bone setters. Tropical Doctor 2000, $133-135$.

[13]. Yinusa W. Ugbeye ME: Problems of amputation surgery in a developing country. Int. Orthop. 2003, $27: 121-124$

[14]. Mansood J, Irfan A, Ghulam M: Current indications for major lower limb amputation. Pakistan J. Surg. 2008, 24(4): 228 - 231.

[15]. Onuminya JE, Onabowale BO, Obekpa PO, Ihezue CH. Traditional bone setters gangrene. Int. Orth. (SICOT) 1999; $23: 111$ - 112.

[16]. Obalum DC, Okeke GC. Lower limb amputations in a Nigerian Private Tertiary Hospital, West African J. Med. 2009; 28(1): 24 27.

[17]. Ekere AE. The scope of extremity amputations in a private hospital in South - South Region of Nigeria, Nig. Journal of Med. 2003; 12(4): $121-124$

[18]. Dada AA, Awoyomi BO. Is the trend of amputation in Nigeria Changing? A review of 51 Consecutive Cases Seen at FMC Ebutte - metta, Lagos, Nigeria, Niger J. Med. 2010; 51(4): 167 - 169.

[19]. Enweluzo GO, Giwa SO, Adekoya - Cole TO, Mofikoya BO. Profile of Amputation in Lagos University Teaching Hospital, Lagos, Nigeria. Nig. Q.J. Hospital Med. 2010; 20: $205-08$.

[20]. Edomwonyi EO, Onuminya JE, Ogbemudia AO, Nwokike OC, Olomu DO, Amputation in Nigeria: The Irrua experience. Journal of Applied and Basic Sciences Vol. 7(1), Dec. 31; 2013.

[21]. Solagberu BA. The Scope of amputations in a Nigerian Teaching Hospital. African J. Med. Sci. 2001 Sept; $30(3): 225$ - 227.

[22]. Ogunlade SO, Alonge IO, Omololu AB et al. Major limb Amputation in Ibadan. Afri. J. Med. Sci. 2002: $31(4)$ : 333 - 336.

[23]. Hassan AW. Major limb amputations in University of Maiduguri Teaching Hospital (1983 - 1989). Medicare Journal 1992. 5(4): 13 $-14$

[24]. Abbas AD, Musa AM: Changing Pattern for extremity amputations in the University of Maiduguri Teaching Hospital, Nigeria. Niger J. Med. 2007 Oct - Dec 16(4): $330-3$

[25]. Olaolorun A.D, Amputation in general practice. The Nig. Postgrad. Med. J. 2001, 8(3): 133 - 135.

[26]. Greive AC, Lankhorst GJ: Functional outcome of lower limb amputees: a prospective descriptive study in a general hospital. Prosthet. Orthot. Int. 1996, 20: $79-87$.

[27]. Pernot HF, Winnubst GM, Cheitmans JJ, De Witte LP: Amputees in Limburg: Incidence, morbidity and mortality, prosthetic supply, care utilization and functional level after one year, Prosthet. Orthot. Int. 2000, 24: 90 - 6.

[28]. Rommers GM, Vos LD, Groothoff JW., Schuiling CH, Eisma WH: Epidemiology of lower limb amputees in the North of the Netherlands; aetiology, discharge destination and prosthetic use. Prosthet Orthot. Int. 1997, 21(2): 92 - 9.

[29]. Unegbu MI, Dim EM. Safer Amputations: A review of 158 cases, Nigerian Journal of Surgical Sciences. $2007: 17(2): 25$ - 32.

[30]. EI Bushra Ahmed Doumi, Aisha Jabir Ali: Major limb amputations in EI Obeid Hospital, Western Sudan. Sudan JMS Vol. 2, No. 4, Dec. 2007.

[31]. Phillipo LC, Joseph BM, Ramesh MD, Isdori H. Ngayamela AB. Chaudika et al, Major limb amputations: A tertiary hospital experience in North Western Tanzania. Journal of Orth. Surg. and Research 2012, 7: 18.

[32]. Muyembe VM, Muhinga MN, Major limb amputation at a provincial general hospital in Kenya, East Africa Med. J. 76 : 163 - 166.

[33]. Naaeder SB. Amputation of the lower limb in Korle - BU Teaching Hospital, Accra. West African J. Med. 1993 , $12: 21$ - 26. 
[34]. Ofaeli R.O. Complications of methods of fracture treatment used by traditional healers: a report of three cases necessitating amputation in ihiala, Nigeria. Trop. Doct. 1991, 21: $182-183$.

[35]. Odatuwa - Omagbemi D.O. Pattern of limb Amputations in Male Patients in a Nigerian Teaching Hospital. Journal of Dental and Medical Sciences Vol. 13, Issue 3, Ver. VI (Mar. 2014). PP $42-5$.

[36]. Cederbergs P, Pritchard D, Joyce J. Doppler - Determined Segmental Pressures and wound healing in Amputations for Vascular Disease. J. Bone and Joint Surg. 65 - A: $363-1983$.

[37]. Chilvers R, Briggs J, Browse N, and Kinmouth J. Below and through the knee amputations in Ischaemic Disease, Br. J. Surg. 58: 824, 1971.

[38]. Cranley J, Krause R, Stausser E, Hofner C: Below Knee amputations for Arleriosclerosis obliterans with or without Diabetes. Arch. Surg. 98: 77, 1969.

[39]. Kihn R, Warren R, Becke G,: The Geriatric Amputee. Ann. Surg. 176: 305, 1972.

[40]. Samiento A, Warren W: A Re-evaluation of lower Extremity Amputations Surgery. Gynaecol. Obstet. 129: 799, 1969.

[41]. Stahlgren L, olfenman M,: Review of Criteria for the selection of the level of lower Extremity Amputations for Arteriosclerosis. Ann Surg. 162: 886, 1965.

[42]. Wagner W, Keagy B, Kolb B, Burnham S, Johnson G: Non-invasive Determination of Major Lower Extremity Amputation Healing: The Continued Role of Clinical Judgment J. Vasc. Surg. 8: 703, 1988.

[43]. Bistrian B, Blackburn G, Hallowell E. And Heddel R: Protein Status of General Surgical Patient's J.A.M.A. 230: 858, 1979.

[44]. Bistrian B, Blackburn G, Vitola J, Cochran D, Naylor J: Prevalence of Malnutrition in general medical patients J.A.M.A. 235, 1567,1976 .

[45]. Law D, Dudrick S, Abdow N: The Effects of Protein Calorie Malnutrition on Immune Competence of the Surgical Patient. Surg. Gynecol. Obstet. 139: 257, 1974.

[46]. Jorue T, Bartlett J, Tally F, Gorbach S: Aerobic and Anaerobic Bacteria in Diabetic foot ulcers. Ann. Intern. Med. 85: 461, 1976.

[47]. Isibor J.O, Samuel S.O, Eyaufe A, Edomwonyi E.O, Odiase V, Elughe J.I et al. Aerobic Bacteria Associated with Diabetic Wounds in Patients Attending Clinic in a rural Community in Nigeria. Global Research Journal of Microbiology Vol. 3(1) pp. 8 - 12 Feb. 2013.

[48]. Shea JD - Surgical Techniques of lower extremity amputation. The Orthopaedic Clinics of North America. 1972; 3(2): $287-301$.

[49]. Peizer E, Wright DW, Manson C. Human locomotion. Bull Porsth. Res. 1969, 10:12.

[50]. High MR, Mcdowell ED, Savrian AR. A critical review of amputation in vascular patients. J. Vascular Surg. 1984, 1: 635 - 655.

[51]. Thompson RG, Complications of lower extremity amputations. The Orthop. Clin. North Ameri. 1972; 3(2): 323 - 338.

[52]. Sie Essoh JB, Kodo M, Dje Bi Dje V, et al, Limb Amputations in adults in an Ivorian Teaching Hospital, Niger J. Clin. Pract. 2009 Sept; 12(3): $245-7$.

[53]. Ajibade A, Akinniyi OT, Okoye CS. Indications and Complications of Major Limb Amputations in Kano, Nigeria, Ghana Medical Journal Vol. 47, Number 4.

[54]. Elachi IC, Songden ZD, Yongu WT, Kortor JN, Mue Daniel D. Causal Conditions for Major Limb Amputations at a Specialist Hospital in North Central Nigeria; Jos Journal of Medicine. Vol. 7, No 2.

[55]. Schley MT, Wilms P, Teopfner S, Schaller HP, Schmelz M, Monrad CJ, et al. Painful and non-painful phantom and stump sensations in acute traumatic injuries. J. Trauma 2008; 65(4): $858-864$

[56]. Brown WA. Post amputation phantom limb pain. Dis. New. Syst. 1968, 29: $301-306$.

[57]. Gangale JP, A review of phantom sensation phenomenon. Virginal Med. Monthly. 1969; 95: 425 - 429.

[58]. Staats TB. The rehabilitation of amputee in developing world: a review of the literature. Prosthet. Orthot. Int. 1996: $20 ; 45-50$.

[59]. Onuminya J.E. A review of lower limb ampution in Nigeria. J. Appl. Bas. Sci. 2004; 2: 1- 4 